\title{
Corona Charged Aerosol Detector non-uniform Response factors of purified Alcohol ethoxylated homologues using Liquid Chromatography
}

\author{
Alizée Dufour $^{a, b}{ }^{,}$Didier Thiébaut ${ }^{b}$, Matthieu Loriau ${ }^{a}$, Leticia Ligiero ${ }^{a}$, Jérôme Vial ${ }^{b}$ \\ ${ }^{a}$ Total S.A. Exploration \& Production - Lacq Research Center (PERL), 64170 Lacq, France \\ ${ }^{b}$ LSABM, UMR CBI 8231, ESPCI Paris - PSL Research University - CNRS, 10 rue Vauquelin, 75005 Paris, France \\ Corresponding author. \\ Email address: alizee.dufour@total.com (Alizee Dufour) \\ Phone number: +33 (0)5 59113353
}

Keywords: Nonionic surfactants, HILIC, Charged Aerosol Detector, Response Factor,

\begin{abstract}
Surfactants are used in various applications: cosmetics, pharmaceuticals, petrochemicals, environmental, etc. Many of these compounds are polydisperse, and because of this intrinsic polydispersity, it is essential to have a universal detector with a uniform response to quantify them in a simple way. Indeed, Charged Aerosol Detector (CAD) was presented as a universal detector with a uniform response. Thus, in the present study, the CAD response, in a High-Performance Liquid Chromatography - CAD configuration (HPLC-CAD), was evaluated using purified alcohol ethoxylated surfactants. A semi-preparative liquid chromatography step using a Hydrophilic interaction chromatography (HILIC) bare silica column $(150 \mathrm{~mm}, 4.6 \mathrm{~mm}, 2.6 \mu \mathrm{m})$ was implemented to prepare eleven homologues of BrijC10, a nonionic surfactant. These homologues differed only by the number of ethylene oxide units. BrijC10 homologues were analyzed by HPLC-CAD, using a HILIC bare silica column $(150 \mathrm{~mm}, 2.1 \mathrm{~mm}, 2.6 \mu \mathrm{m})$ to determine the HPLC-CAD response factors of purified homologues. From the calibration curves (from 100 to $500 \mathrm{mg} \cdot \mathrm{kg}^{-1}$ ), their response factors were estimated: differences in response factors were observed and a maximum difference in response factors of 3.6 was obtained. Thus, it could be concluded that CAD hyphenated to HILIC separation did not present a uniform response for this homologue's distribution.
\end{abstract}

\section{Introduction}


Surfactants, also called "surface active agents", are categorized into four classes: anionic, cationic, nonionic and zwitterionic. The European Committee of organic surfactants and their Intermediates (CESIO) reported more than three million tons of surfactants produced in western Europe in 2018 [1]. The family of alcohol ethoxylates (AEOs) represents half of this production (47\%). This domination is explained by the predominant use of nonionic surfactants in industry (textiles [2,3], cosmetics [4], pharmaceuticals [5,6], agriculture [7], petrochemistry [8-12] etc.) but also in household cleaning products [13-15]. AEOs have a generic chemical formula $\mathrm{CH}_{3}\left(\mathrm{CH}_{2}\right)_{\times}\left(\mathrm{C}_{2} \mathrm{H}_{4} \mathrm{O}\right)_{n} \mathrm{OH}$ with $\mathrm{x}$ ranging from 9 to 19 and $n$ being the number of ethylene oxide units. Despite precautions to avoid surfactant release, traces were found [16-20] in the environment. In order to control surfactants levels in routine, efficient analytical tools are mandatory. Analysis of AEOs is challenging due to their polarity, low volatility and a lack of chromophores.

Traditionally, to perform surfactants analysis, HPLC is hyphenated with absorbance detection (UVVis) [21], fluorescence detection (FL) [22,23] refractive index detection (RI) [24] and evaporative light scattering detection (ELSD) [25]. Recently, mass spectrometry became also a detector of interested $[26,27]$. All these technics present limitations: UV-Vis and FL detection require the presence of chromophore and fluorophore, which are absent in AEOs. Derivatization is possible, but requires an additional step $[13,23]$. Moreover, a cleaning step is also required to eliminate the reactants in excess if the reaction is incomplete, leading to possible loss of compounds and unreliable quantitative analysis. RI detector is not compatible with gradient elution, it is sensitive to temperature and has a low sensitivity [24]. The ionization process in mass spectrometry is molecule dependent. It is also function of the sample matrix and eluent composition. As nonionic surfactants do not have native charges, unlike anionic or cationic surfactants, their ionization is obtained by adduct formation [28]. Moreover, RI, MS, UV-Vis and FL detectors are concentration-dependent. The ELSD shows varied inter-analyte response and intrinsically non-linear calibration curves, but it is the only mass dependent detector [29].

In 2001, Kaufman described for the first time the charged aerosol detection (CAD) in the provisional US patent 6,568,24 [30] which explained the theoretical of CAD. One year later, Dixon and Peterson described an earlier generation, termed aerosol charge detector (ACD) [31]. In 2005, TSI and ESA Biosciences, Inc. collaboration provided the first commercial instrument known under the name Corona CAD. Hyphenated to HPLC system, this detector was claimed to be a universal detector $[32,33]$ because many compounds positively, negatively charged or neutral, with or without a chromophore group, could be analyzed [34]. Hutchinson et al. showed with 23 compounds that 
Corona CAD had an universal response [35]. Detailed reviews of the operating principle of the CAD as a stand-alone detector CAD [32] and hyphenated to HPLC system $[36,37]$ have been published.

Hyphenated to HPLC, like ELSD, CAD is a mass-dependent detector [31,33,38,39]. It means that for equal masses of analytes entering the detector, the HPLC-CAD response is similar. The response should not depend on the spectral or physicochemical properties of the analyte. As many aerosol processes, the HPLC-CAD's response is influenced by the diameter of the generated particles. In their work, Russell et al. explained the relationship between the analyte concentration and the size of the particles [40]. The size of the aerosol particles depends on several factors such as the viscosity of the mobile phase, its density, etc. Indirectly, the HPLC-CAD response depends on the composition of the mobile phase. During a gradient elution, the response will therefore vary as a function of the composition of the mobile phase during the analysis. A technique proposed by Gorecki et al. called mobile-phase compensation can be used to maintain the same composition of mobile phase in the detector [41]. It requires an additional pump to the system in order to deliver the mobile phase compensation. Moreover, a delay volume between the LC pump-CAD (passing through the injector and the column) and the second pump-CAD should be calculated to perform an adequate addition of solvent.

Both CAD and ELSD begin with the nebulization of the mobile phase prior to the detection. However, the HPLC-CAD stands out from the HPLC-ELSD as a more sensitive detector. For example, Kim et al., compared performances of CAD and ELSD hyphenated to HPLC, for the detection of ionic surfactants [34] : the CAD response obtained with anionic surfactants was 1.2 to 2 times greater than the ELSD response. This better sensitivity was also reported by Lobback et al. [42]. Unlike ELSD, CAD detector is supposed to provide a uniform mass response whatever the analyte [38]. Dixit et al. reported an HPLC-CAD method to detect and quantify the Polysorbate 20 content in protein drugs [43]. Ilko et al. confirmed the uniform response thanks to eight fatty acids analyzed by HPLC-CAD. After log-log transformation of concentration and peak area, a linear regression was obtained. In order to compensate for small differences in response between acids, correction factors were calculated and ranged from 0.86 to 1.15. This close values confirmed the uniform HPLC-CAD's response [44]. Gorecki et al. also reported a uniform response for six different sulfonamides which presented close response factors (around 10\% of variability) [41]. Stypulkowska et al. consolidated this trend with two different compounds: neamine and framycetin sulfate. Response factors calculated were 0.91 and 1.1 respectively [45].

In their work, Shi et al. highlighted that the correlation between peak area and polysorbate concentration were not the same between two similar molecules polysorbate 20 and polysorbate 80 
[46]. They explained this difference by the length of fatty acid chains present in PS80, which are longer than in PS20, and induced higher responses on HPLC-CAD. To our knowledge, it was the first time in the literature that the results were not in agreement with the assumption that the response of the HPLC-CAD detector was uniform.

The purpose of the present study was to investigate HPLC-CAD response factors in mass of AEOs homologues. Because these homologues are not commercially available individually at reasonable prices, a semi preparative separation was necessary to isolate BrijC10 homologues to serve as standards. Then, calibration curves were built for each homologue using HILIC-CAD. Response factors of AEO standards in mass could be calculated and compared.

\section{Materials and methods}

\subsection{Chemicals}

LC-MS grade acetonitrile (ACN) and formic acid (FA - 99\%) were purchased from Carlo Erba (Val-deReuil, France). Ammonium formate (99\%) was supplied by Fluka Chemie AG, CH-9470 Buchs. Ultrapure water was obtained from a Milli-Q Purification system from Millipore (Molsheim, France) and used for the preparation solution. Brij ${ }^{\otimes} \mathrm{C} 10$ (BrijC10, Mn 683) was purchased from Sigma Aldrich (Saint-Quentin-Fallavier, France).

\subsection{BrijC10 characterization using HRMS}

To characterize the BrijC10, direct infusion in the Q-Exactive Plus (ThermoFisher, Scientific) orbitrap mass spectrometer with a Heated ElectroSpray II (HESI-II) was done. The syringe pump infused the surfactant solution at $10 \mu \mathrm{L} \cdot \mathrm{min}^{-1}$. For sheath, auxiliary and spare gas, flow rates were respectively 8 psi, 0 (arbitrary unit) and 0 (arbitrary unit.) The spray voltage was set at $3.0 \mathrm{kV}$. The capillary and probe heater temperature were both set at $300{ }^{\circ} \mathrm{C}$. The S-Lens was 50 and the $\mathrm{m} / \mathrm{z}$ range was from 125 to 1000 . The resolution used was $140000 @ 200$, the AGC target was $10^{6}$ and the injected time was 200 ms. Xcalibur 4.2 software (Thermo Scientific) was used for instrument control and data acquisition. FreeStyle (Thermo Scientific) was used for data processing.

\subsection{Alcohol ethoxylated homologues preparation by HILIC semi-preparative system}

Alcohol ethoxylated homologues (AEOs) semi preparative chromatographic separation was performed on a ThermoFisher Scientific Ultimate U3000 HPLC-CAD equipped with SRD-3600 Degasser, RS-3000 pump, WPS 3000 TFC analytical autosampler and TCC-3000-RS column. With the WPS 3000 TFC analytical autosampler, it was possible to do both injection and collection. The column was a HILIC Bare Silica column $(150 \mathrm{~mm}, 4.6 \mathrm{~mm}, 2.6 \mu \mathrm{m})$ from ThermoFisher Scientific. Analytical 
conditions were optimized in our previous published work, but they are recapped as follows [28]. Mobiles phases were ammonium formate $10 \mathrm{mM}$ at pH 3.5 (eluent $\mathrm{A}$ ) and $\mathrm{ACN}$ (eluent B). To achieve separation, the percentage of B was held at $99.9 \%$ for five minutes followed by a decreasing step from $99,9 \%$ to $90 \%$ B within 20 minutes, followed by a final plateau at $90 \%$ B. An equilibration step of five minutes was done before each run at $99.9 \%$. The flow rate was $1.9 \mathrm{~mL} \cdot \mathrm{min}^{-1}$. Oven temperature was $40{ }^{\circ} \mathrm{C}$ and the injection volume was $50 \mu \mathrm{L}$. The maximum collection time was $60 \mathrm{~s}$ according to the collection time frame provided in Table 1. A short collect of $0.1 \mathrm{~min}$ was done before each collect to prevent contamination. 65 runs, with 11 fractions collected per run, were carried out to get enough material. All first fractions were pooled together in the same vial, every second fraction in another and so on until the eleventh fraction. Solvent was evaporated to dryness thanks to a gentle nitrogen flow. The final mass of materials recuperated for each pooled fraction ranged from $1.0 \mathrm{mg}$ to $2.1 \mathrm{mg}$ as shown in Table1. The inter-fraction contamination was checked by high resolution mass spectrometry using Q-Exactive Plus and HPLC-CAD. Moreover, thanks to HRMS, each fraction was attributed and noted AEOn with $\mathrm{n}$ the EO number. Results are presented in Figure S1 (Supporting Information). Using each individual homologue, a calibration was performed with concentrations ranging from 91 to $553 \mathrm{mg} \cdot \mathrm{kg}^{-1}$ in ACN. All samples were analyzed by HILIC-CAD with the analytical method described in section 2.2.

\subsection{Analytical HILIC-CAD system}

HILIC-CAD measurements were performed on a ThermoFisher Scientific Ultimate U3000 HPLC-CAD equipped with SRD-3600 Degasser, RS-3000 pump with two systems, WPS 3000 TFC analytical autosampler, TCC-3000-RS column oven and Corona Veo CAD. The analytical column was an HILIC Bare Silica column $(150 \mathrm{~mm}, 2.1 \mathrm{~mm}, 2.6 \mu \mathrm{m})$ from ThermoFisher Scientific. Mobile phases were ammonium formate $10 \mathrm{mM}$ at $\mathrm{pH} 3.5$ (eluent A) and ACN (eluent B). To achieve separation, the percentage of B was held at $99.9 \%$ for five minutes followed by a decreasing step from $99.9 \%$ to $90 \%$ within 20 minutes. An equilibration step of five minutes was performed before each analysis. The flow rate was $0.4 \mathrm{~mL} \cdot \mathrm{min}^{-1}$. Oven temperature was $40^{\circ} \mathrm{C}$, and the injection volume was $10 \mu \mathrm{L}$.

The principle of Corona CAD can be summarized in three steps. First, the eluent from the liquid chromatography system is nebulized thanks to a gaseous nitrogen stream, creating droplets, which are then dried. Second, the stream of analyte particles is mixed with positively charged nitrogen, obtained by a Corona discharge. Third, charges are transferred to analyte particles. Normally, the signal obtained is proportional to the mass of analytes present in the sample, independently of its chemical structure, properties etc. For this work, CAD evaporator temperature was set at $50^{\circ} \mathrm{C}$, Nitrogen (60 psi) was used for nebulization; a noise filter of $1 \mathrm{~s}$ and a data collection of $10 \mathrm{~Hz}$ were 
used. Parameters that could influence the response of the detector are system dependent: fluctuation of the water/organic solvent ratio, modification of the flow rate, and presence of additives. In order to get rid of these influences, an inverse gradient was applied to maintain the water/organic solvent ratio constant in the detector [41]. The option "Keep solvent composition" was used for the flow calculation of the inverse gradient pump (IGP). The inverse gradient offset volume was $600 \mu \mathrm{L}$ and the flow rate of IGP was $0.4 \mathrm{~mL} \cdot \mathrm{min}^{-1}$. The inverse gradient was as followed: 0-6.5 min $90 \%$ of ACN, $6.5-26.5$ min $90-99.9 \%$ of ACN. In these conditions, the HPLC-CAD response was supposed to be constant during the gradient elution. For data collection and processing, Chromeleon 7 was used.

\section{Results and discussion}

\subsection{BrijC10 characterization by (+)HESI-HRMS}

The purpose of this part was to characterize the nonionic surfactant, BrijC10 in its entirety. Then, from the mass spectrum obtained, homologues chosen for the study were identified. BrijC10 was infused in positive ionization mode to characterize the ions distribution. BrijC10 mass spectrum (Figure 1) was composed of two major distributions. The first one corresponded to singly charged ions ( $\mathrm{m} / \mathrm{z}$ between 400 to 1100 - Figure 1 in blue line), whereas the second one corresponded to doubly charged ions (m/z between 450 to 650 - Figure 1 in red line). BrijC10 was detected with ammonium adducts, $\left[\mathrm{M}+\mathrm{NH}_{4}\right]^{+}$. For AEOs with EO units greater than 15 , double charged ions were also observed. Thanks to the high-resolution, each ion could be identified: the generic molecular formula is $\mathrm{C}_{16} \mathrm{H}_{33} \mathrm{EO}_{n} \mathrm{OH}$ with $\mathrm{n}$ the number of ethylene oxide (EO) ranging from 3 to 28 . The singly charged ions corresponding to isolated homologues are shown in Figure 1, with a blue star. Three ions with $\mathrm{m} / \mathrm{z}=469.3598,491.3727$ and 513.3876 were also noted with a red star. They corresponded to homologues $\mathrm{n}_{\mathrm{EO}}$ from 15 to 17 but doubly charged.

[Figure 1.]

\subsection{Alcohol ethoxylated homologues preparation by HILIC semi-preparative system}

In order to study the response factors of AEO oligomers, a chromatographic separation step was carried out to isolate homologues. An analytical bare silica HILIC column with $4.6 \mathrm{~mm}$ as internal diameter was used for semi preparative purpose. $50 \mu \mathrm{L}$ of BrijC10 solution was injected 65 times to recuperate enough material. The HPLC conditions were selected to have a maximum resolution between homologues and the resulting HPLC-CAD chromatogram is given in Figure 2. As reported by Dufour et al. in HILIC mode retention of oligomers increased according to the number of ethylene oxide units [28]. Throughout the run, and especially in the first ten minutes, the peaks were 
distorted. Indeed, a double peak was observed at 4 minutes. Then, for the distorted peaks at 6,8 and 10 minutes, it seemed that the two peaks merged to form one peak, but this formation is not clear. Peak splitting or distortions can be explained by two phenomena: first, in these first 10 minutes, the presence of water in the mobile phase was very low (1\%). Moreover, these two phenomena could both contribute to the observed behavior. The slightest traces of water in the injected sample could be at the origin of the peak splitting if water content in the sample is higher than in the mobile phase [47]. Second, owing to large volumes and concentration injected, the fused core column may be overloaded, which affected all the more the first eluted compounds $[48,49]$. The more the retention time increased, the more chromatographic dispersion occurred, which limited the overloading consequences on peak shape.

Before each fraction, a little volume was collected. This volume was then thrown out. This short collection was carried out for two reasons. First, when switching from one fraction to another, a drop could fall into the next vial. Second, when the autosampler was not collecting, the injection/collect valve was in the by-passed position, i.e. the mobile phase did not pass in the needle, thus leaving the needle filled with the fluid of the previous fraction. By collecting a small fraction which was then thrown out, it allowed to evacuate the stagnant fluid and therefore to rinse the needle. Figure 2 illustrates the preparative chromatogram of BrijC10 on HILIC bare silica with in dark blue the fractions thrown out, and in light blue the collected fractions which contained AEOs homologues.

[Figure 2.]

As shown, eleven AEOs were isolated and collected. All light blue fractions were analyzed by HILICCAD analytical conditions to check the performance of the separation, i.e. if one fraction was not contaminated by another. The absence of contaminations between fractions was also confirmed because each chromatogram presented a single peak (Figure S1, Supplementary Data). The RPLC analysis of the collected fractions led to quite narrow and symmetrical peaks which made quite unlikely the presence of a mixture of several isobaric isomers in the fractions. Despite this hypothesis could not totally rejected (Figure S2, Supplementary Data). The purity could be estimated between 90 and $98 \%$. Then, the fractions were pooled by fraction for the 65 runs. After dryness under a gentle nitrogen flow, recuperated masses for each homologue were about 1-2 mg. The exact recuperated masses for all AEOs homologues are recapped in Table 1.

[Table 1.]

\subsection{Alcohol ethoxylated response factor in HILIC-CAD}


Once successfully prepared, the AEO standards were used to study the dependence of the system HPLC-Corona CAD response versus the molecular weight. So, response factors of AEO homologues, i.e. with a different number of ethylene oxide units, were compared using five or six different injected masses. The response of the detector was studied using concentrations ranging from 91 mg. $\mathrm{kg}^{-1}$ to $553 \mathrm{mg} \cdot \mathrm{kg}^{-1}$. The calibration curves of the eleven AEOs could be built using the HILIC-CAD analytical method described in section 2.2. A superposition of all the fraction's chromatograms showed that all homologues were analytically resolved (Rs>1.5). Results are given in Figure S3 (in Supplementary Data).

Calibration curves were obtained from peak areas and consisted of five to six points. They are provided in Figure 3. In the rest of the article, homologues will be noted by AEOn with $\mathrm{n}$ being the number of ethylene oxide units, for example $A E O 11$ is the homolog $\mathrm{C}_{16} \mathrm{H}_{33} \mathrm{EO}_{11} \mathrm{OH}$. All homologues presented linear responses, with determination coefficients between 0.9866 (AEO10) and 0.9993 (AEO12) (Table 2).

[Figure 3.]

In the present study, the response factor was estimated by the slope of the calibration curve. The slope $(\mathrm{m})$ was ranging from 1.84 to 6.61 with standard deviations between 0.03 to 0.33 . All response factors were normalized to the maximum value (AEO10) in order to keep variations between 0 and 1 . This normalization step permitted also to compare response factor evolution obtained with mass and molar concentrations (Figure 4-(A) and Figure 4-(B) respectively). Even if the CAD, in HPLC-CAD system, is known as being mass-depend, the evolution of the molar response factors was also investigated. Mass concentrations, expressed here in $\mathrm{mg} \mathrm{kg}^{-1}$, were converted to molar concentration in mol. $\mathrm{L}^{-1}$. Standard deviations of the slope (SDm) were also represented as error bars. For AEO16 and AEO17, SDm were $4 \%$ and $7 \%$ respectively while for the other homologues it was rather $2-3 \%$. This higher uncertainty could be explained by the low mass recuperated during the sample preparation which increased the uncertainty on the calculated concentrations. Figure 4 shows that the CAD detector in HPLC-CAD system did not present the same response for BrijC10 homologues differing by their number of EO units. The response factor increased with the number of EO until $\mathrm{n}_{\mathrm{EO}}=10$. From this value, a diminution was observed according to the EO number until it stabilized towards $\mathrm{n}_{\mathrm{EO}}=15$. A factor of 2 was found between AEO7 and AEO10 and 3.6 between AEO15 and AEO10. This atypical evolution was similar in case of molar response factor. Moreover, homologues AEO15, AEO16 and AEO17 were detected in HRMS both singly and doubly charged. Their response factor observed followed the same trend as those observed for single-charged homologues in HRMS. The state of charge did not influence the response factor. Currently, there is no explication about this 
similar response. As announced in the introduction but also in section 2.2 , the signal depends on the number of charges detected. They themselves depend on the accessible surface and therefore on the size of the particles formed during nebulization step [40]. Until now, no study was found to explain this behavior, only assumptions could be done. The increase in the response factor as a function of the increase in the number of EOs, could be due to the formation of particles having a higher surface and therefore a greater capacity to be charged. The decrease observed between $n=10$ and 15 could suggest here that despite their larger size the molecules are more difficult to charge. Comparison with a mass spectrometer could be considered. Today, only a few studies have hypothesized that homologues of the same type have a different response, but none have offered proof or explanations $[46,50]$. In order to deepen the explanation of this phenomenon, molecular modeling could be considered to understand how molecules are organized together during the formation of particles. In addition, investigations could be carried out on the measurement of the size of the droplets formed according to the number of EO in the molecules. They could be carried out by a low angle linear segment detector (LSD). All suppliers present the Charged Aerosol Detector, hyphenated to HPLC, as a uniform detector, i.e. the response of all compounds is the same. If the detector had a uniform response, response factors should be the same for all the homologues. Definitely, our results show it is not the case as can be seen on Figure 4 .

\section{[Figure 4.]}

\section{[Table 2.]}

From calibration curves, the Limit of Detection (LD) and the Limit of Quantification (LQ) were determined, based on the residual standard deviation of the regression and on the slope of the calibration curve (Table 2) [51]. LDs for all AEO homologues were below $40 \mathrm{mg} \cdot \mathrm{kg}^{-1}$ and LQs were under $100 \mathrm{mg} \cdot \mathrm{kg}^{-1}$, except for AEO10. These values could not be compared with the literature values, because articles reported quantification by family and not by homologues as done in this study.

\section{Conclusion}

The main objective of the project was to quantify the polydisperse surfactants from petrochemical industry. Using HPLC-CAD seemed to be the best alternative, as it is supposed to respond uniformly in mass regardless of the number of monomers. This would have the advantage of overcoming the response coefficients given the large number of structures to be separated. In this purpose, response factors of pure homologues of a nonionic surfactant obtained with a HPLC-Corona CAD system were compared. The nonionic surfactant selected for this study was the BrijC10 $\left(\mathrm{C}_{16} \mathrm{H}_{33} \mathrm{EO}_{n} \mathrm{OH}\right.$ and Mn 630). After a preparative HILIC separation, eleven homologues having a number of ethylene 
oxide units from 7 to 17 were isolated from the BrijC10 distribution. Response factors were calculated from calibration curves between $100 \mathrm{mg} \cdot \mathrm{kg}^{-1}$ to $500 \mathrm{mg} \cdot \mathrm{kg}^{-1}$. The evolution of response factor as a function of EO units, showed that the CAD detector response in HPLC-CAD system could vary by a factor of more than 3 from one homologue to one another. Assumption about the different spatial conformations according to the EO number could explain this phenomenon. The modeling of these molecules could help its understanding and would make the object of a new study. LDs were below $40 \mathrm{mg} \cdot \mathrm{kg}^{-1}$ and LQs were under $100 \mathrm{mg} \cdot \mathrm{kg}^{-1}$, except for AEO10.

\section{Acknowledgements}

This work was a collaboration between the École Supérieure de Physique et de Chimie Industrielles (ESPCI-PARIS PSL University), Paris, France and TOTAL, Lacq, France. The authors acknowledge Total for allowing to publish these results as well as for the financial support.

\section{References}

[1] European Committee of organic surfactants and their Intermediates, Surfactant Production EU 1994-2018, 2018.

[2] X. Luo, L. Zhang, Z. Niu, X. Ye, Z. Tang, S. Xia, Liquid chromatography coupled to quadrupoleOrbitrap high resolution mass spectrometry based method for target analysis and suspect screening of non-ionic surfactants in textiles, J. Chromatogr. A 1530 (2017) 80-89. https://doi.org/10.1016/j.chroma.2017.11.001.

[3] M. Castillo, F. Ventura, D. Barcelo, Sequential solid phase extraction protocol followed by liquid chromatography-atmospheric pressure chemical ionization-mass spectrometry for the trace determination of non ionic polyethoxylated surfactants in tannery wastewaters, Waste Management (1999) 101-110.

[4] S.H. Im, Y.H. Jeong, J.J. Ryoo, Simultaneous analysis of anionic, amphoteric, nonionic and cationic surfactant mixtures in shampoo and hair conditioner by RP-HPLC/ELSD and LC/MS, Anal. Chim. Acta 619 (2008) 129-136. https://doi.org/10.1016/j.aca.2008.03.058.

[5] G. Vanhoenacker, M. Steenbeke, K. Sandra, P. Sandra, Profiling Nonionic Surfactants Applied in Pharmaceutical Formulations by Using Comprehensive Two-Dimensional LC with ELSD and MS Detection, LC GC North America 36 (2018) 385-393. 
[6] S. Almeling, D. Ilko, U. Holzgrabe, Charged aerosol detection in pharmaceutical analysis, J. Pharm. Biomed. Anal. 69 (2012) 50-63. https://doi.org/10.1016/j.jpba.2012.03.019.

[7] K.A. Krogh, B.B. Mogensen, B. Halling-Sørensen, A. Cortés, K.V. Vejrup, D. Barceló, Analysis of alcohol ethoxylates and alkylamine ethoxylates in agricultural soils using pressurised liquid extraction and liquid chromatography-mass spectrometry, Anal. Bioanal. Chem. 376 (2003) 1089-1097. https://doi.org/10.1007/s00216-003-2062-3.

[8] A. Bhardwaj, S. Hartland, Applications of Surfactants in Petroleum Industry, J. of Dispersion Sc. \& Tech. 14 (1993) 87-116. https://doi.org/10.1080/01932699308943389.

[9] P. Raffa, A.A. Broekhuis, F. Picchioni, Polymeric surfactants for enhanced oil recovery: A review, Journal of Petroleum Science and Engineering 145 (2016) 723-733. https://doi.org/10.1016/j.petrol.2016.07.007.

[10] C. Negin, S. Ali, Q. Xie, Most common surfactants employed in chemical enhanced oil recovery, Petroleum 3 (2017) 197-211. https://doi.org/10.1016/j.petlm.2016.11.007.

[11] Y. Bai, C. Xiong, X. Shang, Y. Xin, Experimental Study on Ethanolamine/Surfactant Flooding for Enhanced Oil Recovery, Energy Fuels 28 (2014) 1829-1837. https://doi.org/10.1021/ef402313n.

[12] E.M. Thurman, I. Ferrer, J. Blotevogel, T. Borch, Analysis of hydraulic fracturing flowback and produced waters using accurate mass: identification of ethoxylated surfactants, Anal. Chem. 86 (2014) 9653-9661. https://doi.org/10.1021/ac502163k.

[13] L. Ripoll-Seguer, M. Beneito-Cambra, J.M. Herrero-Martínez, E.F. Simó-Alfonso, G. Ramis-Ramos, Determination of non-ionic and anionic surfactants in industrial products by separation on a weak ion-exchanger, derivatization and liquid chromatography, J. Chromatogr. A 1320 (2013) 66-71. https://doi.org/10.1016/j.chroma.2013.10.046.

[14] J.-M. Park, H.-J. Kim, J.-H. Lee, J.-M. Kim, Determination of Anionic Surfactants in Dishwashing Detergents by High-performance Liquid Chromatography, Food Eng. Prog. 20 (2016) 211-217. https://doi.org/10.13050/foodengprog.2015.20.3.211.

[15] F. Motteran, P.C.F. Lima Gomes, E.L. Silva, M.B.A. Varesche, Simultaneous determination of anionic and nonionic surfactants in commercial laundry wastewater and anaerobic fluidized bed reactor effluent by online column-switching liquid chromatography/tandem mass spectrometry, Sci. Total Environ. 580 (2017) 1120-1128. https://doi.org/10.1016/j.scitotenv.2016.12.068.

[16] C. Fernández-Ramos, O. Ballesteros, R. Blanc, A. Zafra-Gómez, F.J. Camino-Sánchez, A. Navalón, J.L. Vílchez, Determination of alcohol sulfates and alcohol ethoxysulfates in marine and river 
sediments using liquid chromatography-tandem mass spectrometry, Talanta 115 (2013) 606615. https://doi.org/10.1016/j.talanta.2013.05.058.

[17] J.M. Traverso-Soto, P.A. Lara-Martín, V.M. León, E. González-Mazo, Analysis of alcohol polyethoxylates and polyethylene glycols in marine sediments, Talanta 110 (2013) 171-179. https://doi.org/10.1016/j.talanta.2013.02.027.

[18] J.M. Traverso-Soto, P.A. Lara-Martín, E. González-Mazo, V.M. León, Distribution of anionic and nonionic surfactants in a sewage-impacted Mediterranean coastal lagoon: inputs and seasonal $\begin{array}{lllll}\text { variations, Sci. } & \text { Total } & \text { Environ. }\end{array}$ https://doi.org/10.1016/j.scitotenv.2014.06.107.

[19] J. Zembrzuska, I. Budnik, Z. Lukaszewski, Monitoring of selected non-ionic surfactants in river water by liquid chromatography-tandem mass spectrometry, J. Environ. Manage. 169 (2016) 247-252. https://doi.org/10.1016/j.jenvman.2015.12.034.

[20] V. Gomez, L. Ferreres, E. Pocurull, F. Borrull, Determination of non-ionic and anionic surfactants in environmental water matrices, Talanta $84 \quad$ (2011) 859-866. https://doi.org/10.1016/j.talanta.2011.02.009.

[21] A. Escrig-Doménech, M. Beneito-Cambra, E.F. Simó-Alfonso, G. Ramis-Ramos, Single-pump heart-cutting two-dimensional liquid chromatography applied to the determination of fatty alcohol ethoxylates, J. Chromatogr. A 1361 (2014) 108-116. https://doi.org/10.1016/j.chroma.2014.07.092.

[22] S. Zhang, Z. Yu, N. Hu, Y. Sun, Y. Suo, J. You, Sensitive determination of melamine leached from tableware by reversed phase high-performance liquid chromatography using 10-methylacridone-2-sulfonyl chloride as a pre-column fluorescent labeling reagent, Food Control 39 (2014) 25-29. https://doi.org/10.1016/j.foodcont.2013.10.037.

[23] M. Fujita, Y. Yamamoto, S. Wanibuchi, Y. Katsuoka, T. Kasahara, A newly developed means of HPLC-fluorescence analysis for predicting the skin sensitization potential of multi-constituent substances using ADRA, Toxicol. In Vitro 59 (2019) 161-178. https://doi.org/10.1016/j.tiv.2019.04.014.

[24] A. Trani, G. Gambacorta, P. Loizzo, A. Cassone, C. Fasciano, A.V. Zambrini, M. Faccia, Comparison of HPLC-RI, LC/MS-MS and enzymatic assays for the analysis of residual lactose in lactose-free milk, Food Chem. 233 (2017) 385-390. https://doi.org/10.1016/j.foodchem.2017.04.134. 
[25] M.I. Malik, S. Lee, T. Chang, Comprehensive two-dimensional liquid chromatographic analysis of $\begin{array}{llllll}\text { poloxamers, } & \text { J. } & \text { Chromatogr. } & \text { A } & 1442 & \text { (2016) 33-41. }\end{array}$ https://doi.org/10.1016/j.chroma.2016.03.008.

[26] Z.-y. Wu, P.J. Marriott, One- and comprehensive two-dimensional high-performance liquid chromatography analysis of alkylphenol polyethoxylates, J. Sep. Sci. 34 (2011) 3322-3329. https://doi.org/10.1002/jssc.201100701.

[27] V. Elsner, S. Laun, D. Melchior, M. Köhler, O.J. Schmitz, Analysis of fatty alcohol derivatives with comprehensive two-dimensional liquid chromatography coupled with mass spectrometry, J. Chromatogr. A 1268 (2012) 22-28. https://doi.org/10.1016/j.chroma.2012.09.072.

[28] A. Dufour, D. Thiébaut, L. Ligiero, M. Loriau, J. Vial, Chromatographic behavior and characterization of polydisperse surfactants using Ultra-High-Performance Liquid Chromatography hyphenated to High-Resolution Mass Spectrometry, J. Chromatogr. A 1614 (2020) 460731. https://doi.org/10.1016/j.chroma.2019.460731.

[29] B.T. Mathews, P.D. Higginson, R. Lyons, J.C. Mitchell, N.W. Sach, M.J. Snowden, M.R. Taylor, A.G. Wright, Improving Quantitative Measurements for the Evaporative Light Scattering Detector, Chromatographia 60 (2004) 625-633. https://doi.org/10.1365/s10337-004-0441-3.

[30] S. Kaufman, Evaporative electrical detector, US Patent 6,568,245 (2003).

[31] R.W. Dixon, D.S. Peterson, Development and testing of a detection method for liquid chromatography based on aerosol charging, Anal. Chem. 74 (2002) 2930-2937. https://doi.org/10.1021/ac011208l.

[32] I.N. Acworth, W. Kopaciewicz, Charged Aerosol Detection: A Literature Review, 2017.

[33] A. Hazotte, D. Libong, M. Matoga, P. Chaminade, Comparison of universal detectors for hightemperature micro liquid chromatography, J. Chromatogr. A 1170 (2007) 52-61. https://doi.org/10.1016/j.chroma.2007.09.008.

[34] B.-H. Kim, J.B. Jang, D.C. Moon, Analysis of ionic surfactants by HPLC with Evaporative Light Scattering Detection and Charged Aerosol Detection, Journal of Liquid Chromatography \& Related Technologies 36 (2013) 1000-1012. https://doi.org/10.1080/10826076.2012.683915.

[35] J.P. Hutchinson, J. Li, W. Farrell, E. Groeber, R. Szucs, G. Dicinoski, P.R. Haddad, Universal response model for a corona charged aerosol detector, J. Chromatogr. A 1217 (2010) 74187427. https://doi.org/10.1016/j.chroma.2010.09.056. 
[36] R.A. Shalliker (Ed.), Hyphenated and Alternative Methods of Detection in Chromatography, CRC Press, 2011

[37] M. Ligor, S. Studzińska, A. Horna, B. Buszewski, Corona-Charged Aerosol Detection: An Analytical Approach, Critical Reviews in Analytical Chemistry 43 (2013) 64-78. https://doi.org/10.1080/10408347.2012.746134.

[38] P. Gamache, R. McCarthy, S. Freeto, R. Cole, HPLC Analysis of Nonvolatile Analytes Using Charged Aerosol Detection, LCGC North America 23 (2005) 150-161.

[39] A. Stojanovic, M. Lämmerhofer, D. Kogelnig, S. Schiesel, M. Sturm, M. Galanski, R. Krachler, B.K. Keppler, W. Lindner, Analysis of quaternary ammonium and phosphonium ionic liquids by reversed-phase high-performance liquid chromatography with charged aerosol detection and $\begin{array}{llllll}\text { unified calibration, J. Chromatogr. A } 1209 & \text { (2008) }\end{array}$ https://doi.org/10.1016/j.chroma.2008.09.017.

[40] J.J. Russell, J.C. Heaton, T. Underwood, R. Boughtflower, D.V. McCalley, Performance of charged aerosol detection with hydrophilic interaction chromatography, J. Chromatogr. A 1405 (2015) 72-84. https://doi.org/10.1016/j.chroma.2015.05.050.

[41] T. Górecki, F. Lynen, R. Szucs, P. Sandra, Universal response in liquid chromatography using charged aerosol detection, Anal. Chem. 78 (2006) 3186-3192. https://doi.org/10.1021/ac060078j.

[42] Lobback C, Backensfeld T, Funke A, Weitschies W., Analysis of polysorbate 80 using fast HPLC and charged aerosol detection, Pharm Tech 34 (2010) 48-54.

[43] N. Dixit, N. Salamat-Miller, P.A. Salinas, K.D. Taylor, S.K. Basu, Residual Host Cell Protein Promotes Polysorbate 20 Degradation in a Sulfatase Drug Product Leading to Free Fatty Acid Particles, J. Pharm. Sci. 105 (2016) 1657-1666. https://doi.org/10.1016/j.xphs.2016.02.029.

[44] D. Ilko, A. Braun, O. Germershaus, L. Meinel, U. Holzgrabe, Fatty acid composition analysis in polysorbate 80 with high performance liquid chromatography coupled to charged aerosol detection, Eur. J. Pharm. Biopharm. 94 (2015) 569-574. https://doi.org/10.1016/j.ejpb.2014.11.018.

[45] K. Stypulkowska, A. Blazewicz, Z. Fijalek, M. Warowna-Grzeskiewicz, K. Srebrzynska, Determination of neomycin and related substances in pharmaceutical preparations by reversedphase high performance liquid chromatography with mass spectrometry and charged aerosol 
detection, J. Pharm. Biomed. Anal. 76 (2013) 207-214. https://doi.org/10.1016/j.jpba.2012.12.025.

[46] S.S. Zhi Chen, A Highly Sensitive Method for the Quantitation of Polysorbate 20 and 80 to Study the Compatibility between Polysorbates and $\mathrm{m}$-Cresol in the Peptide Formulation, J Anal Bioanal Tech 06 (2015). https://doi.org/10.4172/2155-9872.1000245.

[47] B. Chauve, D. Guillarme, P. Cléon, J.-L. Veuthey, Evaluation of various HILIC materials for the fast separation of polar compounds, J. Sep. Sci. 33 (2010) 752-764. https://doi.org/10.1002/jssc.200900749.

[48] C.B. Castells, R.C. Castells, Peak distortion in reversed-phase liquid chromatography as a consequence of viscosity differences between sample solvent and mobile phase, J. Chromatogr. A 805 (1998) 55-61.

[49] J.C. Heaton, D.V. McCalley, Some factors that can lead to poor peak shape in hydrophilic interaction chromatography, and possibilities for their remediation, J. Chromatogr. A 1427 (2016) 37-44. https://doi.org/10.1016/j.chroma.2015.10.056.

[50] B. Trathnigg, M. Kollroser, C. Rappel, Liquid exclusion adsorption chromatography, a new technique for isocratic separation of nonionic surfactants, J. Chromatogr. A 922 (2001) 193-205. https://doi.org/10.1016/S0021-9673(01)00938-4.

[51] J. Vial, A. Jardy, Experimental Comparison of the Different Approaches To Estimate LOD and LOQ of an HPLC Method, Anal. Chem. 71 (1999) 2672-2677. https://doi.org/10.1021/ac981179n. 


\section{Figures captions}

Figure 1: Mass spectrum of BrijC10 in (+)HESI-HRMS with orbitrap as analyzer - Blue stars indicated the singly charged ions corresponding to isolated homologues, red stars indicated the doubly charged ions corresponding to isolated homologues

Figure 2: Chromatogram of BrijC10 in HILIC-CAD semi-preparative conditions (2.1.) - Dark blue indicates fractions thrown out and light blue collected fractions composed of AEOs homologues

Figure 3: Calibration curves of AEO standards in HILIC-CAD analytical conditions 2.2.

Figure 4: Evolution of the response factors (normalized) of BrijC10 homologues as a function of their molecular weight $-(A)$ in mass concentration condition and (B) in molar concentration conditions

Table 1: Collection time frame with mass recuperated $( \pm 0.1 \mathrm{mg})$ for each fraction

Table 2: Statistics of AEOs calibration curves in HPLC-CAD using HILIC column, the slope correspond to the response factor 


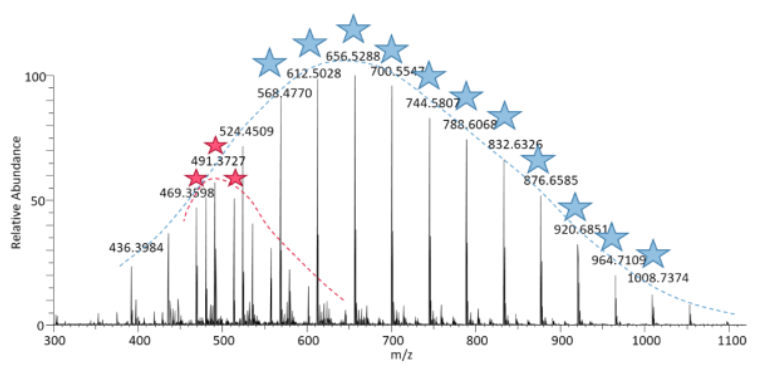

Figure 1 : Mass spectrum of BrijC10 in (+)HESI-HRMS with orbitrap as analyzer - Blue stars indicated the singly charged ions corresponding to isolated homologues, red stars indicated the doubly charged ions corresponding to isolated homologues

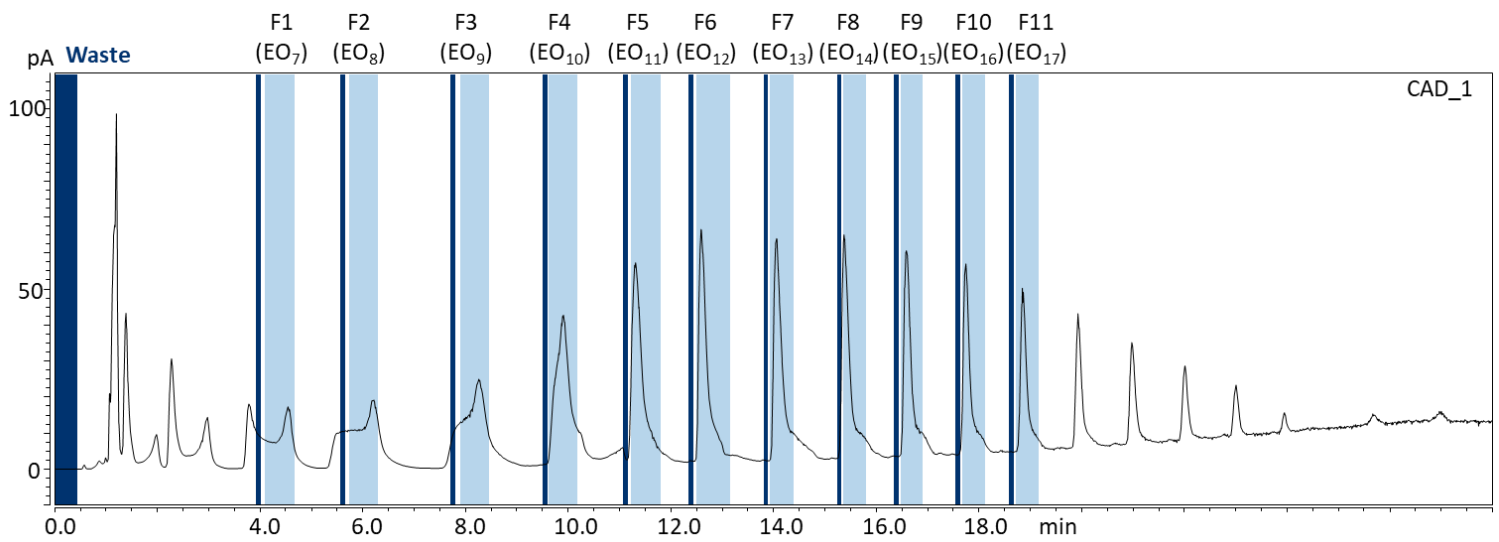

Figure 2 : Chromatogram of BrijC10 in HILIC-CAD semi-preparative conditions (2.1.) - Dark blue indicates fractions thrown out and light blue collected fractions composed of AEOs homologues

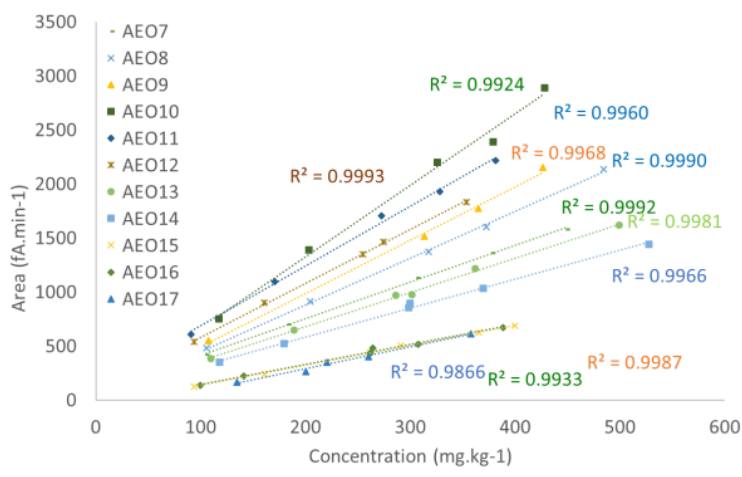

Figure 3 : Calibration curves of AEO standards in HILIC-CAD analytical conditions 2.2. 


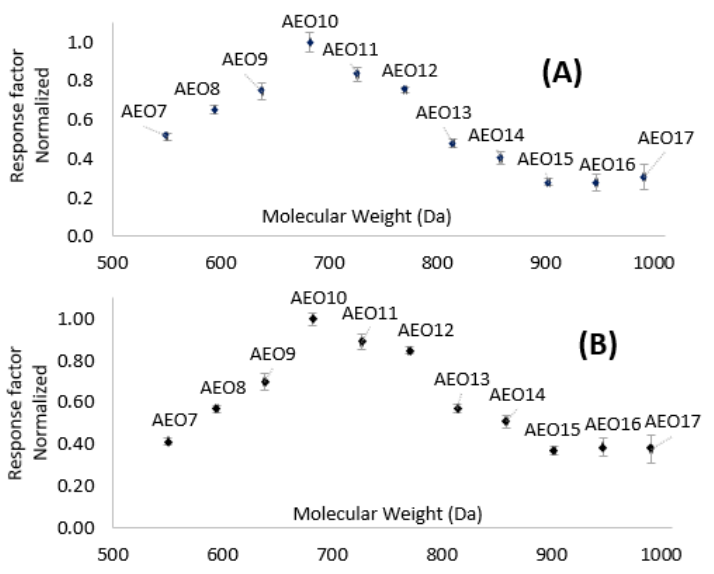

Figure 4 : Evolution of the response factors (normalized) of BrijC10 homologues as a function of their molecular weight - (A) in mass concentration condition and (B) in molar concentration conditions

\begin{tabular}{ccccc}
\hline $\begin{array}{c}\text { Start collect } \\
(\mathrm{min})\end{array}$ & $\begin{array}{c}\text { End collect } \\
(\mathbf{m i n})\end{array}$ & Name & $\begin{array}{c}\text { Recuperated } \\
\text { mass }\end{array}$ & Attribution \\
\hline 4.00 & 4.60 & Fraction 1 & $2.1 \mathrm{mg}$ & AEO7 \\
5.55 & 6.30 & Fraction 2 & $2.1 \mathrm{mg}$ & AEO8 \\
7.70 & 8.40 & Fraction 3 & $2.0 \mathrm{mg}$ & AEO9 \\
9.60 & 10.25 & Fraction 4 & $2.1 \mathrm{mg}$ & AEO10 \\
11.15 & 11.75 & Fraction 5 & $1.8 \mathrm{mg}$ & AEO11 \\
12.50 & 12.90 & Fraction 6 & $1.8 \mathrm{mg}$ & AEO12 \\
13.95 & 14.50 & Fraction 7 & $1.6 \mathrm{mg}$ & AEO13 \\
15.25 & 15.70 & Fraction 8 & $1.6 \mathrm{mg}$ & AEO14 \\
16.45 & 16.80 & Fraction 9 & $1.4 \mathrm{mg}$ & AEO15 \\
17.55 & 17.90 & Fraction 10 & $1.3 \mathrm{mg}$ & AEO16 \\
18.75 & 19.10 & Fraction 11 & $1.0 \mathrm{mg}$ & AEO17 \\
\hline
\end{tabular}

Table 1 : Collection time frame with mass recuperated $( \pm 0.1 \mathrm{mg})$ for each fraction 


\begin{tabular}{ccccccc}
\hline Name & Slope (SDm) & Intercept (SDb) & SDy & $R^{2}$ & LD (mg.kg-1) & LQ (mg.kg-1) \\
\hline AEO7 & $3.39(0.06)$ & $74.2(17.3)$ & 15.7 & 0.9992 & 14 & 46 \\
\hline AEO8 & $4.32(0.08)$ & $18.0(26.2)$ & 23.7 & 0.9990 & 16 & 55 \\
\hline AEO9 & $4.94(0.10)$ & $1.80(64.8)$ & 47.6 & 0.9968 & 29 & 96 \\
\hline AEO10 & $6.61(0.33)$ & $2.70(105.0)$ & 85.8 & 0.9924 & 39 & 130 \\
\hline AEO11 & $5.53(0.20)$ & $138.0(54.8)$ & 47.7 & 0.9960 & 26 & 86 \\
\hline AEO12 & $4.98(0.07)$ & $84.1(18.0)$ & 14.9 & 0.9993 & 9 & 30 \\
\hline AEO13 & $3.17(0.07)$ & $44.5(21.8)$ & 20.9 & 0.9981 & 20 & 66 \\
\hline AEO14 & $2.67(0.08)$ & $50.6(25.6)$ & 25.3 & 0.9966 & 28 & 95 \\
\hline AEO15 & $1.85(0.03)$ & $-46.8(9.5)$ & 8.7 & 0.9987 & 14 & 47 \\
\hline AEO16 & $1.84(0.07)$ & $-38.6(19.9)$ & 18.1 & 0.9933 & 30 & 98 \\
\hline AEO17 & $2.03(0.14)$ & $-117.0(33.7)$ & 22.6 & 0.9866 & 33 & 111 \\
\hline
\end{tabular}

Table 2 : Statistics of AEOs calibration curves in HPLC-CAD using HILIC column, the slope correspond to the response factor 


\section{Corona Charged Aerosol Detector non-uniform Response factors of purified}

\section{Alcohol ethoxylated homologues using Liquid Chromatography}

Alizée Dufour $^{a, b}$, Didier Thiébaut $^{b}$, Matthieu Loriau ${ }^{a}$, Leticia Ligiero $^{a}$, Jérôme Vial ${ }^{b}$

${ }^{a}$ Total S.A. Exploration \& Production - Lacq Research Center (PERL), 64170 Lacq, France

${ }^{b}$ LSABM, UMR CBI 8231, ESPCI Paris - PSL Research University - CNRS, 10 rue Vauquelin, 75005 Paris, France

Corresponding author.

Email address: alizee.dufour@total.com (Alizee Dufour)

Phone number: +33 (0)5 59113353

\section{Supplementary data}

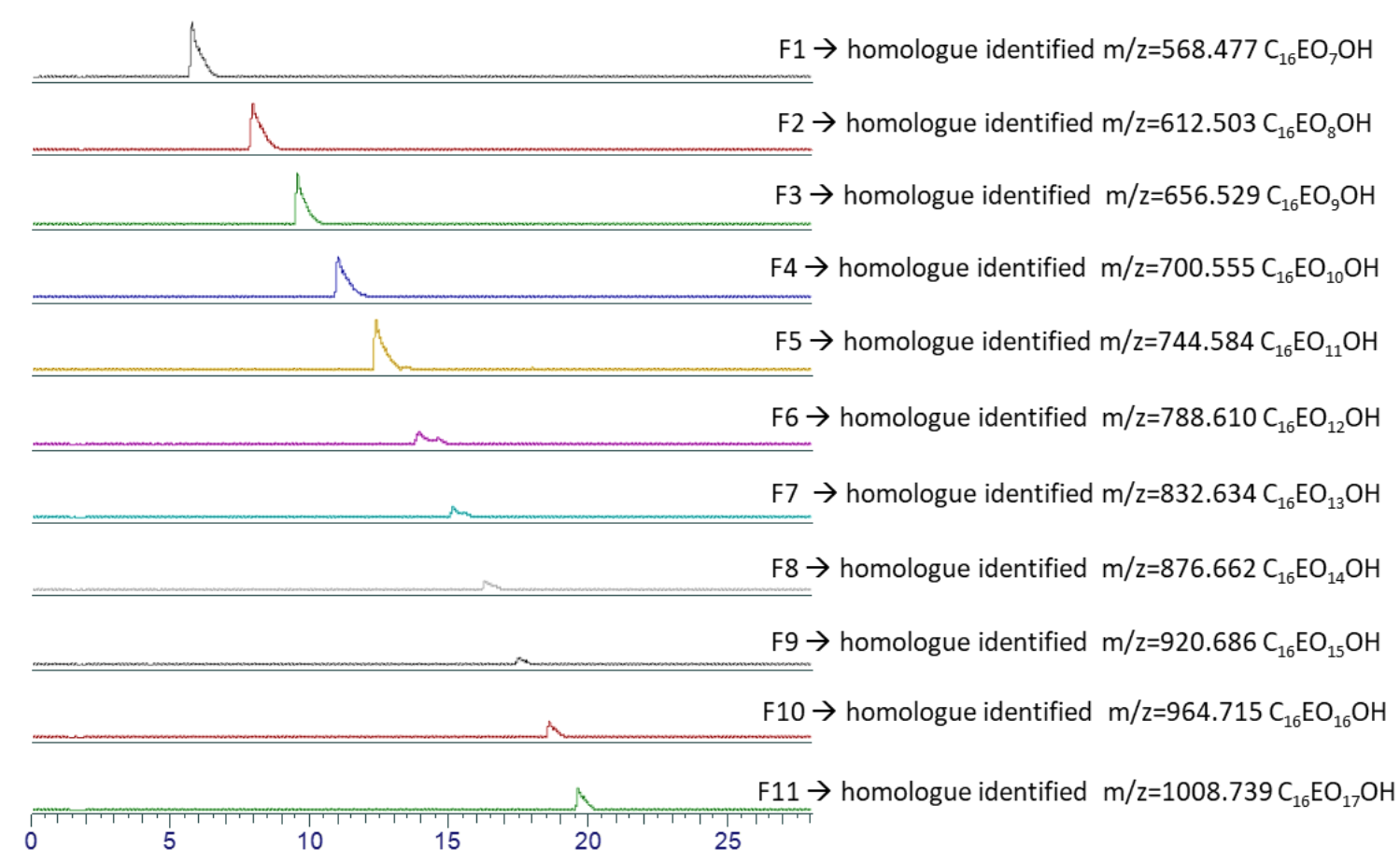

EICs:568.479,612.505,656.531,700.557,744.584,788.610,832.636,876.662,920.688,964.715,1008.741,425.335,447.348,469.361, $491.375,513.388 \pm 5 p p m$

Figure S1: Stack EICs ( $\pm 5 p p m)$ of BrijC10 homologues by HILIC-HRMS - no contamination and identification of AEO presented in each fraction 


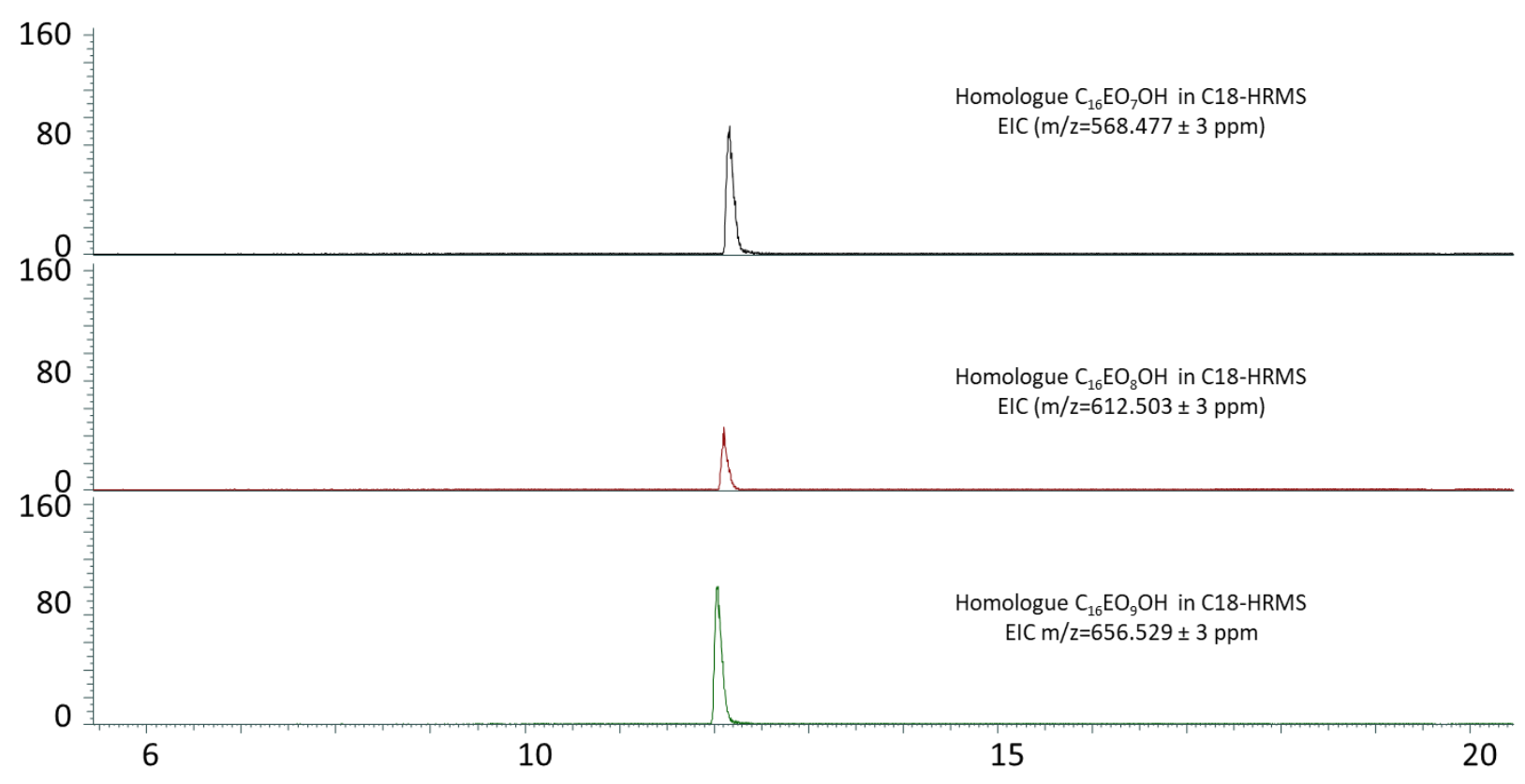

Figure S2: AEO7, AEO8 and AEO9 chromatographs on HPLC-(+)HRMS using C18 column - No presence of a mixture of several isobaric isomers. Analytical conditions: mobile phase: ammonium formate $10 \mathrm{mM}$ pH 3.5/ ACN - LC gradient: 30-100\% of ACN in 20 min.

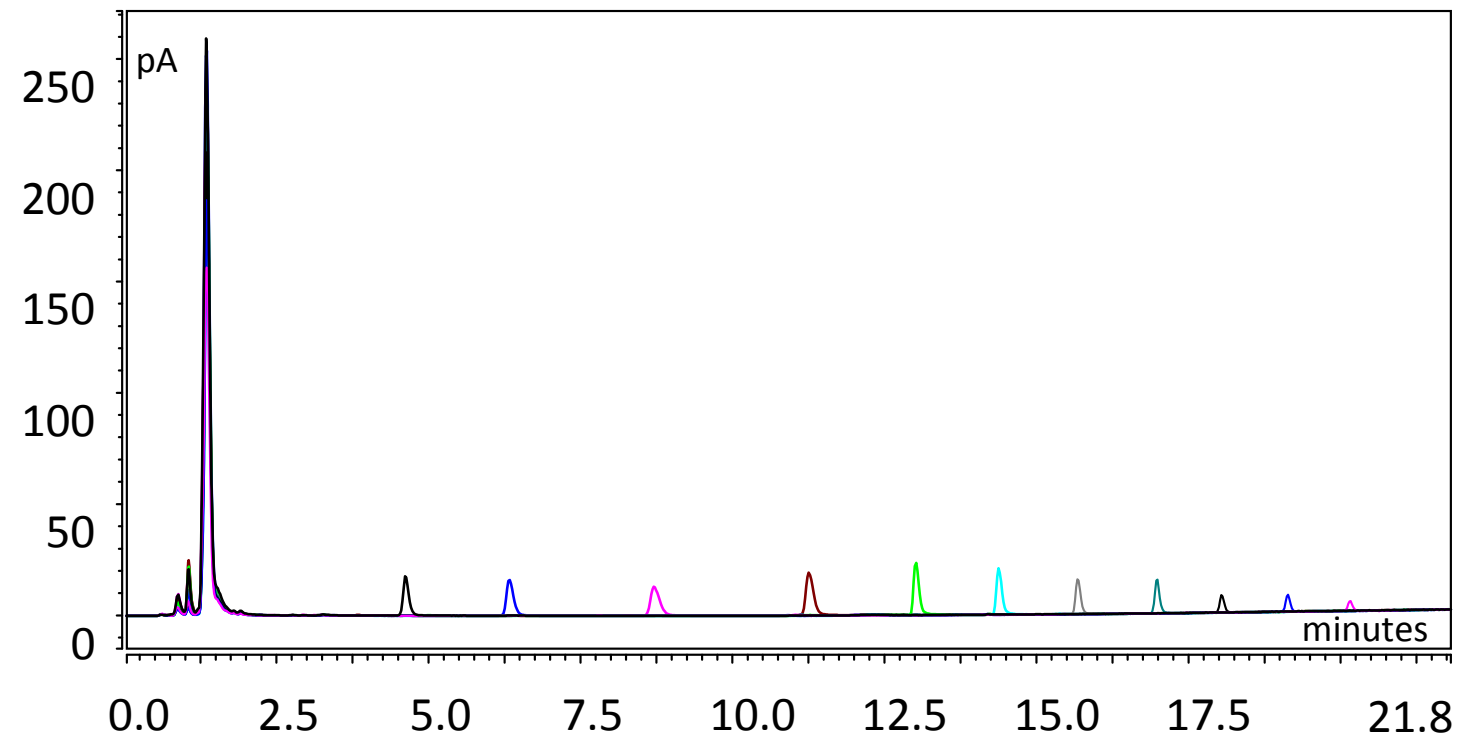

Figure S3: Overlays of chromatograms AEOs in HILIC-CAD 